\title{
Sleep, Orexin and Cognition
}

\author{
Balmeet Toor ${ }^{a}$ Laura B. Ray ${ }^{a, b} \quad$ Alyssa Pozzobon $^{a}$ Stuart M. Fogel ${ }^{a-c}$ \\ aSchool of Psychology, University of Ottawa, Ottawa, ON, Canada; ${ }^{b}$ Sleep Unit, The Royal's Institute of \\ Mental Health Research, University of Ottawa, Ottawa, ON, Canada; ' ${ }^{C}$ University of Ottawa Brain and Mind Research \\ Institute, Ottawa, ON, Canada
}

\begin{abstract}
Orexins regulate a wide variety of biological functions, most notably the sleep-wake cycle, reward and stress processing, alertness, vigilance, and cognitive functioning. Alterations of central and peripheral orexin levels are linked to conditions such as narcolepsy, anorexia nervosa, age-related cognitive decline, and neurodegenerative disease. Preliminary studies suggest that orexin mimetics can safely promote the wake signal via orexin agonism during the day and that orexin receptor antagonists can promote the sleep signal during the night. Thus, novel orexin therapies have the potential to either improve memory, cognition, and daytime performance directly or indirectly, through promotion of good sleep. The full scope of the therapeutic potential of orexin therapies remains to be elucidated.
\end{abstract}

(c) 2021 The Author(s)

Published by S. Karger AG, Basel

\section{Introduction}

Orexin-A and -B (also known as hypocretin 1 and 2, respectively) are neuropeptides whose main function is the regulation of the sleep-wake cycle $[1,2]$. However, they are also involved in the regulation of a wide variety of other critical body functions such as feeding behavior, energy balance, stress responses, reward processing, mood, and cognition (for a review, see [3]). Dysfunction of the orexin system may therefore underlie a variety of different pathological conditions. Much of this knowledge comes from investigations of the role of orexins in narcolepsy [4], a sleep disorder characterized by chronic daytime sleepiness, sleep attacks, rapid eye movement (REM) sleep abnormalities, and in 
some cases (narcolepsy type 1), cataplexy (i.e., the sudden loss of muscle tone). While the links between orexin deficits and narcolepsy [5-7], as well as between narcolepsy and cognitive deficits $[8,9]$, are relatively well established, it is debated whether orexin dysfunction and cognitive deficits such as memory, executive control and attention problems, which are observed in narcolepsy are directly linked in humans.

Here, we examine the link between the orexin system and cognition. We begin with a description of the orexin system. We then discuss the orexin-related cognitive deficits and the potential of orexin receptor modulators as a treatment for the cognitive deficits seen in narcolepsy, anorexia nervosa, normal aging, and neurodegenerative disease. Pertinent animal models will be included, where appropriate; however, a thorough review of the animal literature on this topic is beyond the scope of the current review.

\section{The Neurobiology of the Orexin System}

Orexin-A and -B are excitatory neuropeptides synthesized in the lateral hypothalamus and perifornical areas $[10,11]$. Orexin- $A$ is composed of 33 amino acids, while orexin- $B$ is composed of 28 amino acids; both are derived from the same precursor (prepro-orexin) by proteolytic processing $[10,11]$. The activity of orexin-A and -B are mediated by Gprotein-coupled orexin receptors: $\mathrm{OX}_{1} \mathrm{R}$ and $\mathrm{OX}_{2} \mathrm{R} ; \mathrm{OX}_{1} \mathrm{R}$ has a higher affinity for orexinA than orexin-B, while $\mathrm{OX}_{2} \mathrm{R}$ binds both orexins with the same affinity [12]. The ability of orexin- $\mathrm{A}$ and $-\mathrm{B}$ to act on different locations in the brain is due to the vast distribution of orexin receptors, throughout much of the central nervous system (see Fig. 1 for details) [13]. Notably, several of these brain areas, including the hypothalamus, basal forebrain, tuberomammillary nucleus (TMN), periaqueductal gray, dorsal raphe (DR), and locus coeruleus (LC) regulate sleep-wake states and promote arousal. In addition, several of these areas support memory and cognitive function, notably, the hippocampus and prefrontal cortex. The orexin system is also modulated by a variety of neurotransmitters and neuromodulators, e.g. glutamate [14], gamma-aminobutyric acid (GABA) [15], noradrenaline, and serotonin [16].

More specifically, orexins regulate sleep and wake via dense projections from orexin neurons in the lateral hypothalamus that innervate and activate serotonergic neurons in the DR [17], noradrenergic neurons in the LC [18], and histaminergic neurons in the TMN [19]. Orexins also have an excitatory effect on cholinergic neurons in the basal forebrain (thought to regulate arousal [20]), the pedunculopontine tegmental (PPT) nucleus and the laterodorsal tegmental nucleus [21, 22], all regions thought to regulate REM sleep and wakefulness. Interestingly, $\mathrm{GABA}_{\mathrm{B}}$ agonism of the PPT reduces REM sleep (and in turn, promotes wakefulness) by inhibiting cholinergic REM-on neurons and consequently, impairs sleep-dependent memory consolidation [23]. $\mathrm{OX}_{1} \mathrm{R}$ mRNA is exclusively expressed in cholinergic neurons of the PPT, whereas both $\mathrm{OX}_{1} \mathrm{R}$ and $\mathrm{OX}_{2} \mathrm{R}$ mRNA are expressed in GABAergic interneurons of the PPT [24]. This suggests that modulation of orexin signaling might be one putative way to impact memory con- 


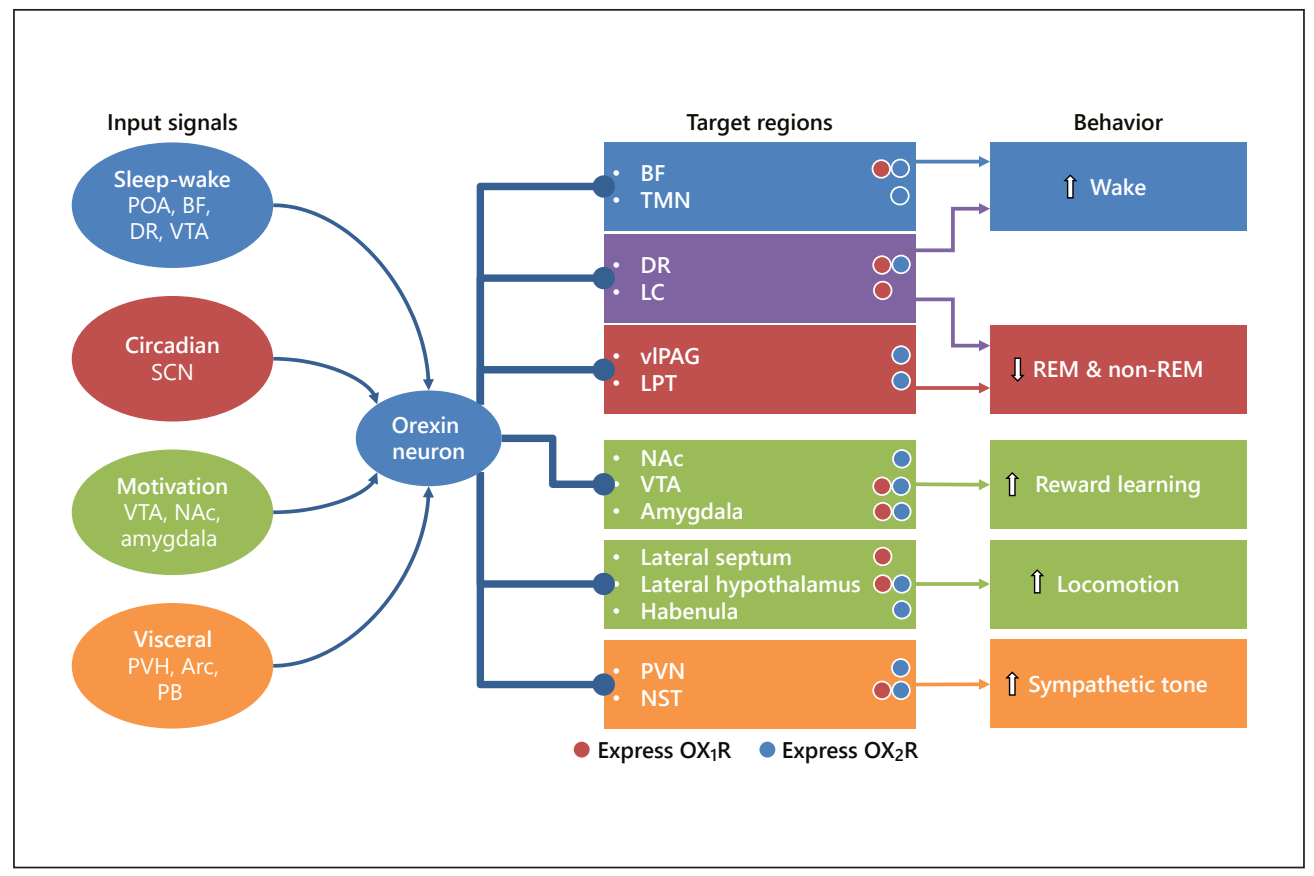

Fig. 1. Inputs and outputs of orexin neurons. Orexin neurons receive input signals from regions related to sleep-wake states, circadian phase, motivation, and visceral cues (e.g., amino acid levels, $\mathrm{CO}_{2}$ ). In turn, these neurons send output signals to a variety of brain regions related to maintaining wakefulness, suppressing and regulating rapid eye movement (REM) and non-REM sleep, enhancing responses to rewards and learning, increasing locomotion and autonomic/sympathetic tone. The orexin neuropeptides bind to orexin type 1 (red circles: $\mathrm{OX}_{1} \mathrm{R}$ ) and type 2 (blue circles: $\mathrm{OX}_{2} \mathrm{R}$ ) receptors. Through these diverse connections, the orexin neurons integrate a variety of inputs to promote arousal. Several orexinergic pathways innervate brain areas that directly support other aspects of cognition such as reward learning and locomotion. Orexin may also have an indirect influence on memory and cognition through the promotion of sleep. Arc, arcuate nucleus; BF, basal forebrain; DR, dorsal raphe; LC, locus coeruleus; LPT, lateral pontine tegmentum; NAc, nucleus accumbens; NST, nucleus of the solitary tract; PB, parabrachial nucleus; $\mathrm{POA}$, preoptic area; $\mathrm{PVH}$, paraventricular nucleus of the hypothalamus; $\mathrm{PVN}$, paraventricular nucleus; SCN, suprachiasmatic nucleus; TMN, tuberomammillary nucleus; vIPAG, ventrolateral periaqueductal gray; VTA, ventral tegmental area. Adapted from Mahoney et al. [45] with permission from Springer Nature.

solidation via regulation of REM sleep in the PPT; however, this possibility remains to be tested. Orexins are also understood to be involved in higher-order cognitive functions such as attention, executive control, and memory, presumably due to their role in maintaining the excitability of pyramidal neurons in the prefrontal cortex (for a review, see [25]). Evidence has consistently shown that orexins enhance cognitive function [26-29], whereas the effects of orexin antagonism on cognitive function are far less established. For example, orexin antagonists have been shown to cause cognitive dysfunction [30], while other studies have observed that they may not impair cognitive functioning [3134]. More research is required to elucidate if orexin antagonism impacts cognitive functioning. 


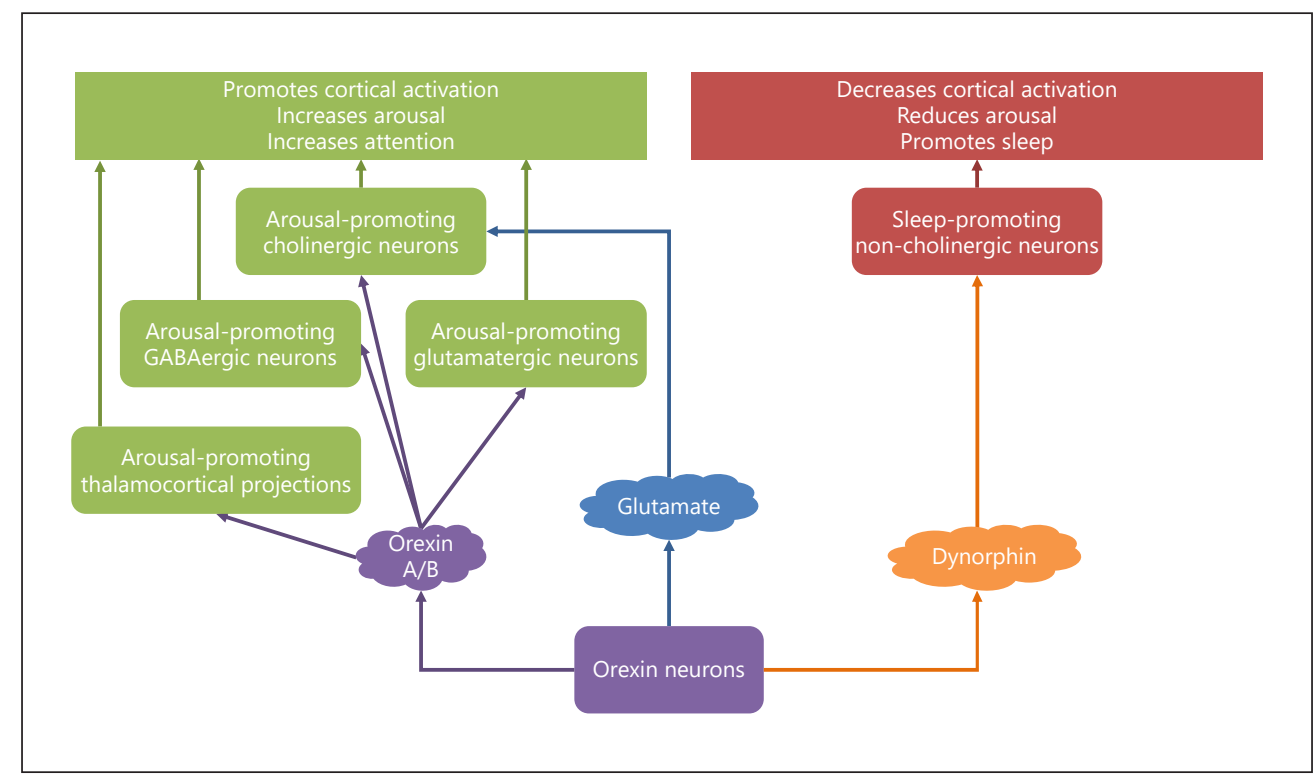

Fig. 2. Pathways through which orexins may promote cognition. In response to salient stimuli, orexin neurons produce several neuropeptides which promote cortical activation and attention by acting ultimately on cholinergic neurons. Adapted from Vilano et al. [107] with permission under the Creative Commons Attribution 4.0 International (CC BY 4.0) License (https://creativecommons.org/licenses/ by/4.0/).

\section{The Orexin System as a Target for Treating Cognitive Deficits}

When investigating the neural correlates of cognitive functioning in conditions with orexin dysfunction and possible therapeutic targets, it is important to consider the possibility that neuropsychological deficits could be due to sleep deprivation per se, rather than a specific underlying neuropathology in the orexin system. Thus, cognitive deficits may not be directly due to dysfunctions in orexin signaling and may represent a secondary outcome of sleepiness rather than pathogenesis of orexin deficiencies. However, this possibility remains to be directly investigated. While it is crucial to understand the mechanism of action, in either case, orexin therapies may prove to be therapeutic for cognitive health. Preliminary studies suggest that orexin mimetics can safely promote the wake signal via orexin agonism during the day, and orexin receptor antagonists can promote the sleep signal during the night. For example, dual orexin receptor antagonists (DORAs), including daridorexant, suvorexant and lemborexant, have been found to be effective in reducing insomnia symptoms and improving sleep, e.g. reducing latency to persistent sleep, subjective total sleep time, and wake after sleep onset [35-37]. Further, preliminary findings from a recent phase 3 clinical trial revealed that for daridorexant administration, there were no negative cognitive side effects and, as compared to placebo, improved daytime performance (e.g., less physically/mentally tired, less daytime sleepiness, improved energetic feelings) from baseline at month 1 and 3 [35]. Thus, novel 
orexin therapies have the potential to either improve memory, cognition, and daytime performance directly or indirectly, through promotion of good sleep (Fig. 2). The full scope of the therapeutic potential of orexin therapies in the treatment of cognitive and sleep symptoms in narcolepsy, anorexia, normal aging, and neurodegenerative disease is largely unexplored and remains to be elucidated. The following sections will review the limited evidence that currently exists and highlight the need for future research in such conditions.

\section{Narcolepsy}

Gélineau first coined the term "narcolepsy" in 1880 to describe a sleep disorder characterized by excessive daytime sleepiness and episodic muscle weakness triggered by strong emotions [38]. This episodic muscle weakness was later termed cataplexy [39]. The clinical diagnostic criteria [4] eventually evolved into two forms of narcolepsy: types 1 and 2. Both types have overlapping symptoms that include excessive daytime sleepiness, "sleep attacks" (i.e., the sudden and irresistible urge to fall asleep), sleep paralysis (i.e., the feeling of being unable to move, either during sleep onset or upon awakening), hypnagogic hallucinations (i.e., dream-like visions during sleep onset), REM sleep at sleep onset and other abnormalities of nocturnal sleep (e.g., reduced sleep latency, increased wake and stage 1 sleep after sleep onset, and decreased slow wave sleep) [40], as well as cognitive deficits (discussed further, below). However, symptoms are more severe in narcolepsy type 1 , which is somewhat less common than type 2 (25-50 per 100,000 people for narcolepsy type 1 vs. 56 per 100,000 people for narcolepsy type 2) [41]. Narcolepsy type 1 is primarily distinguished by cataplexy and low or undetectable orexin-A levels in the cerebrospinal fluid (CSF) [42, 43]. The reduced orexin levels result from a severe loss of orexin neurons in the lateral hypothalamus $[7,44]$, the cause of which remains unknown. However, the prevailing theory is that narcolepsy type 1 is an autoimmune disease mediated by $\mathrm{T}$ cells (for a review, see [45]). The cause of narcolepsy type 2 remains unknown and no specific biomarker exists for it. In addition, only narcolepsy type 1 is considered a clearly defined entity, due to the existence of a specific diagnostic biomarker for the disorder, i.e. low or absent orexin levels in the CSF. As a result, much of the research investigating narcolepsy focuses on the less heterogeneous narcolepsy type 1-diagnosed patients.

In terms of cognitive deficits, individuals with narcolepsy often report difficulties with memory, learning, and concentration [46]; however, results have varied regarding objective performance deficits, particularly for working memory. While some studies have shown intact working memory performance in patients with narcolepsy [9, 47], others have found modest $[9,48]$ or significant $[49]$ memory impairments. More consistent evidence exists for attention and executive function deficits in narcolepsy. Several studies have consistently reported slower and more variable reaction times in patients with narcolepsy versus control subjects [50-52]. This has been shown for monotonous tasks that 
require vigilance and sustained attention [49], but not focused attention or verbal memory [47]. By contrast, patients with narcolepsy perform poorly when divided and flexible attention is required, as well as for tasks that require monitoring and manipulating information on-line [9, 52], decision-making, and reward processing [53-55]. Cognitive dysfunction in narcolepsy type 1 is consistent with problems associated with the allocation of cognitive resources [9], thought to be due to low orexin-A levels [6, 7]. Thus, orexin-A deficiencies may impact cognitive control processes that require sustained attention over long periods of time and adversely impact working memory [9], for which there could be downstream consequences for learning and long-term memory. However, much work remains to be done to determine if this is the case for narcolepsy type 1 or 2 , and whether this is directly related to orexin, or indirectly via sleep disturbances.

The majority of studies investigating the treatment of narcolepsy by targeting the orexin system in both animals and human have investigated alleviating the sleep symptoms only and have largely overlooked behavioral changes and related cognitive deficits [18, 56]. That said, studies in rhesus macaque monkeys and in human narcoleptic patients found that intranasal orexin-A administration promotes wakefulness and improves shortterm memory and attention deficits associated with sleep loss $[26,57,58]$. This increase in attention and short-term memory is thought to arise from cortical activation via orexin-mediated increases in acetylcholine (Fig. 2). Taken together, these studies support a therapeutic use for orexin receptor agonists as a therapy in narcolepsy.

However, since it is unclear whether orexin loss is causally related to memory deficits in narcolepsy or whether it is linked secondarily to poor sleep or excessive daytime sleepiness, future studies could, for example, compare treatment responses in terms of both sleep-related symptoms and cognitive symptoms in narcoleptic patients treated with: (1) orexin agonists, (2) non-orexin drug therapies, and (3) placebo/no treatment to determine whether orexin is directly related to cognitive outcomes. A number of studies have investigated non-orexin agonist medications, including sodium oxybate, modafinil, and pitolisant, in terms of reducing daytime sleepiness and cataplexy (for a review, see [59]). However, to our knowledge, no studies to date have investigated the impact of these medications on the cognitive deficits associated with narcolepsy.

\section{Anorexia Nervosa}

Patients with anorexia nervosa present with severely restricted eating behavior, low body weight, and an intense fear of weight gain [60]. In addition, they show altered decisionmaking [61], set-shifting [62], central coherence (i.e., an information processing imbalance, biasing local details over the global "gist") [63], and delay discounting (i.e., degree of preference for immediate gratification over larger delayed rewards) [64]. Steward et al. [62] identified that reduced plasma orexin-A levels were associated with impairments in the ability to unconsciously shift attention between one task and another (i.e., set-shifting) in patients with anorexia nervosa. This observation suggests that reduced orexin levels 
may impact cognition in anorexia nervosa. However, considering the role of orexins in the regulation of feeding, stress, and reward processing, as well as cognition, their involvement in the pathophysiology of anorexia nervosa is complex and remains poorly understood. At present, results are sparse, and findings vary. For example, across different studies, plasma orexin-A levels in patients with anorexia nervosa have been found to be higher [65], lower [66], and not significantly different from control patients [67]. Moreover, Sauchelli et al. [67] investigated both sleep disturbances and orexin levels in anorexia and found that, although there were no global differences between anorexic patients and healthy controls in terms of plasma orexin-A concentrations, higher orexin-A concentrations within the group of anorexia patients was associated with greater sleep disturbances [67]. In addition, both elevated orexin-A concentrations and inadequate sleep predicted poorer treatment outcome.

To date, no studies have directly targeted the orexin system as a treatment for the cognitive deficits seen in anorexia nervosa. Additional research is needed to resolve the inconsistencies in the literature regarding orexin-A levels in patients with this disorder [62, 65-67]. Given that elevated orexin-A concentrations in anorexia nervosa are associated with inadequate sleep [67], future studies could use orexin receptor antagonists to prevent excessive orexin signaling, promote sleep and potentially also improve cognitive health in anorexia nervosa.

\section{Normal Aging}

One of the earliest signs of age-related cognitive decline is a deterioration of attention [68, 69]. Anatomical evidence suggests that with increasing age, a selective loss of orexin neurons, orexin peptides, and their receptors occurs [70,71]. The target areas of these orexin projections, such as the prefrontal cortex and basal forebrain, are strongly implicated both in normal cognitive function and in age-related cognitive decline [72-75]. Taken together, these observations suggest that the orexin system is a potential therapeutic target to mitigate or improve age-related cognitive decline. However, this possibility remains to be experimentally tested.

It is increasingly evident that sleep, physical activity, and cognition are interconnected, which has been suggested to be especially important for the aging brain (for a review, see [76]). It is plausible that orexin loss contributes to cognitive decline in normal aging, whether directly related to cognitive performance or indirectly via sleep and activity. Researchers have identified that intranasal orexin-A administration increased prefrontal cortical acetylcholine release and consequently improved attentional function (e.g., setshifting) in aging rats [28]. However, to date, no studies have directly targeted the orexin system via orexin receptor agonism as a treatment for the cognitive deficits seen in normal aging in humans. 


\section{Neurodegenerative Disease}

\section{Alzheimer's Disease}

Alzheimer's disease $(\mathrm{AD})$ is a neurodegenerative disease, characterized by progressive cognitive deficits and behavioral impairments. The pathogenesis of $\mathrm{AD}$ involves excess extracellular $\beta$-amyloid deposition leading to neuronal degeneration, hyperphosphorylation of tau protein, and the formation of neurofibrillary tangles, which undermine the normal functioning of neurons and synapses (for a review, see [77]). Evidence suggests $[78,79]$ a positive correlation between AD biomarkers and orexin. For example, animal models of $\mathrm{AD}$ suggest that sleep disturbances observed in $\mathrm{AD}$ patients are hypothesized to be mediated by an increase in the expression of orexins [80, 81]. Further evidence in mice and humans suggests that sleep disruption may exacerbate the progression of $\mathrm{AD}$ neuropathology and cognitive deterioration, including memory problems (for a review, see [82]). However, other evidence [83] suggests that $\mathrm{AD}$ is associated with the loss of orexin-containing neurons and some impairment in orexin neurotransmission. Taken together, this indicates that the orexin system plays a potential role in $\mathrm{AD}$ pathogenesis, although more research is needed to understand the links between possible orexin dysfunction in $\mathrm{AD}$ and the impact of this on cognition.

To date, the majority of research investigating AD and the orexin system has focused on orexin antagonists to promote the sleep signal. Based on the brain waste hypothesis for the function of sleep, overactivity in the orexin system is associated with abnormalities in sleep patterns and $\beta$-amyloid levels $[81,84]$. For example, in a transgenic mouse model of AD, both wakefulness and interstitial fluid levels of $\beta$-amyloid decreased with daily infusion of the orexin antagonist, almorexant, while they both increased with intracerebroventricular administration of orexin [81]. In amyloid transgenic mice in which the orexin gene was knocked out, loss of orexin resulted in decreased wakefulness and a subsequent reduction in amyloid pathology [84]. Conversely, rescuing orexinergic neurons in the hypothalamus in orexin knockout mice increased the amount of $\beta$-amyloid pathology in the brain [84]. Overexpression of orexins only in the hippocampus, however, did not increase $\beta$-amyloid expression, demonstrating that orexins do not affect $\beta$-amyloid production directly, but rather indirectly through the modulation of wakefulness [84]. This may be explained by two physiological mechanisms: (1) during sleep, the brain removes toxins including $\beta$-amyloid through glymphatic clearance [85], and, (2) more $\beta$-amyloid is produced during wakefulness, when neurons are firing more strongly [86], than during sleep [87]. Therefore, orexin receptor agonists could increase $\beta$-amyloid production and decrease glymphatic clearance by promoting wakefulness. Taken together, evidence suggests that targeting the orexin system via orexin receptor antagonists, but not agonists, has therapeutic potential in the treatment of cognitive and sleep symptoms in AD. It is worth noting that significant disruption to circadian-related timing of sleep-wake cycles is also observed in $\mathrm{AD}$ (for a review, see [88]); however, the possible therapeutic application for orexin therapies to regulate circadian rhythms in $\mathrm{AD}$, related neuropathology, disease progression, and any related 
benefit to memory and cognition remains unexplored. Few studies have investigated whether chronic administration of a DORA would enhance sleep and reduce neuropathology, neuroinflammation and cognitive deficits. For example, in an AD mouse model (5XFAD), a DORA increased sleep and restored natural sleep patterns [89]. Moreover, neuropathological and neuroinflammatory markers were unaffected. However, the 5XFAD mice did not exhibit the expected cognitive deficits; therefore, it was not possible to evaluate whether DORA-induced improvements in sleep would benefit cognitive functions [89].

\section{Parkinson's Disease}

Parkinson's disease (PD) is characterized by motor and non-motor symptoms including mood, cognition, and metabolic impairments; with the non-motor symptoms preceding development of the motor symptoms $[90,91]$. The pathogenesis of PD involves the loss of dopamine neurons, primarily in the substantia nigra and the formation of Lewy bodies. In PD, orexin levels are reduced in CSF $[92,93]$. The increasing loss of orexin neurons is observed as PD progresses [94, 95], and orexin circuitry dysfunction has been attributed to disordered sleep $[96,97]$. However, the impact of orexin dysfunction in PD on cognition remains unexplored, despite the distinct possibility that there might be important consequences for cognitive health.

Activation of orexinergic neurotransmission can lead to the synthesis of brain-derived neurotrophic factor (BDNF) which may be therapeutic in the prevention of dopamine neuron loss in PD. BDNF plays an important role in neuronal survival and growth, and BDNF is reduced in the substantia nigra of PD patients [98]. Thus, BDNF promotion via orexin therapies may provide neuroprotection in PD. For example, direct administration of orexin-A and -B to dopamine neurons of the substantia nigra increased spontaneous neuronal firing and improved behavioral and motor symptoms induced by administration of the dopamine antagonist haloperidol. By contrast, orexin receptor antagonism reduced firing of dopamine neurons in the substantia nigra [99]. Similarly, orexin-A administration in 6-OHDA-treated rats (a compound used to induce dopaminergic neuronal degeneration in rodents to mimic PD) improved motor function, whereas administration of an orexin receptor antagonist in 6-OHDA-treated rats decreased motor function [100]. To date, only a single animal study [101] has targeted the orexin system to investigate its potential for treating cognitive deficits seen in PD and found that both pharmacological orexin intervention (i.e., intrahippocampal injections of orexin-A) and orexin neuron-specific genetic intervention (i.e., chemogenetic viral injections of the orexin neuron-specific designer receptor exclusively activated by designer drug [DREADD], clozapine N-oxide) improved hippocampal-dependent memory impairment in a mouse model of PD. The effect of orexin therapy on cognitive and motor symptoms in PD remains to be experimentally tested in humans. 


\section{Conclusions}

Orexins may modulate cognition and memory function. Orexins also regulate a wide variety of bodily functions including the sleep-wake cycle, feeding behavior, energy balance, and mood, all known to impact cognitive functioning. It is not clear whether orexins relate directly or indirectly to memory and cognition via these factors. Importantly, when investigating the relationship between orexin system dysfunction and cognitive functioning, it is important to consider that cognitive deficits could be ascribed to poor sleep quality, rather than directly to orexin pathology. In other words, cognitive deficits in conditions with abnormal orexin signaling, could therefore be a secondary outcome of symptoms related to sleep disturbance, rather than be directly related to orexin pathology per se. This is an important area where future research is needed to understand the full spectrum of the therapeutic potential for orexin treatments. One possible strategy to improve daytime performance, attention, and memory in conditions such as narcolepsy, anorexia nervosa, normal aging, and neurodegenerative disease is to promote the wake signal via orexin receptor agonism during the day. Alternatively, another interesting possibility is to leverage the well-established links between sleep, memory, and cognition (for a review, see [102]). In this case, orexin receptor antagonism during the night could be employed to promote good sleep, which may have both direct and indirect benefits to memory, cognition, and daytime performance. Importantly, this review of the relevant literature highlights the great need for more research on this topic, especially given the widespread and diverse neural pathways that rely on input from orexins, and which support a wide range of biological functions such as sleep, feeding behaviors, mood, and cognition. One particularly promising avenue of future research would be to explore the therapeutic benefit of orexin drug therapies for memory by normalizing REM abnormalities in conditions with orexin abnormalities. Specifically, REM sleep has been shown to support, in particular, memory that involves procedures and skills which rely on cognitively complex rules, grammar, logic, and reasoning [103, 104], and non-REM sleep supports motor skills memory and declarative memory [105, 106]. Future studies employing orexin therapies that enhance both nocturnal REM and non-REM sleep (e.g., DORAs) may lead to novel treatments for the various symptoms, conditions, and disorders, including anorexia nervosa and neurodegenerative disease. In the case of narcolepsy (type 1) where orexin receptor antagonists may be contraindicated, orexin agonists during the daytime may help to normalize nocturnal sleep, thus providing optimal conditions for sleep to support normal cognitive functioning. Orexin research may reveal novel therapeutic treatments for not only primary symptoms, but also for memory and cognition either directly, or indirectly through the improvements of daytime alertness and improved sleep.

\section{Key Take-Home Points}

- Orexins benefit wakefulness, vigilance, memory, and cognition.

- Orexins regulate various biological functions that indirectly and directly impact memory, cognition, and daytime performance. 
- Orexin receptors are a potential novel therapeutic target to improve cognition in sleep disorders, age-related cognitive decline, and neurodegenerative disease.

- The link between orexins, their impact on wakefulness and vigilance, and memory and cognition remains to be thoroughly investigated.

\section{Conflict of Interest Statement}

S.M.F. received consultancy fees from Idorsia Pharmaceuticals Ltd during the development of this book. The authors declare no other conflicts of interest.

\section{Funding Sources}

The authors have no funding to declare.

\section{Author Contributions}

All authors were involved in the development and review of the chapter, approved the final version to be published and take responsibility for all aspects of the work.

\section{References}

1 Chemelli RM, Willie JT, Sinton CM, Elmquist JK, Scammell T, Lee C, et al: Narcolepsy in orexin knockout mice: molecular genetics of sleep regulation. Cell 1999;98: 437-451.

2 Lin L, Faraco J, Li R, Kadotani H, Rogers W, Lin X, et al: The sleep disorder canine narcolepsy is caused by a mutation in the hypocretin (orexin) receptor 2 gene. Cell 1999;98:365-376.

3 Chieffi S, Carotenuto M, Monda V, Valenzano A, Villano I, Precenzano F, et al: Orexin system: the key for a healthy life. Front Physiol 2017;8:357.

4 American Academy of Sleep Medicine. International Classification of Sleep Disorders Third Edition. Darien, American Academy of Sleep Medicine, 2014.

5 Nishino S, Ripley B, Overeem S, Lammers GJ, Mignot E: Hypocretin (orexin) deficiency in human narcolepsy. Lancet 2000;355:39-40.

6 Peyron C, Faraco J, Rogers W, Ripley B, Overeem S, Charnay Y, et al: A mutation in a case of early onset narcolepsy and a generalized absence of hypocretin peptides in human narcoleptic brains. Nat Med 2000;6: 991-997.

7 Thannickal TC, Moore RY, Nienhuis R, Ramanathan L, Gulyani S, Aldrich MS, et al: Reduced number of hypocretin neurons in human narcolepsy. Neuron 2000;27: 469-474.

8 Rieger M, Mayer G, Gauggel S: Attention deficits in patients with narcolepsy. Sleep 2003;1:36-43.
9 Naumann A, Bellebaum C, Daum I. Cognitive deficits in narcolepsy. J Sleep Res 2006;15:329-338.

10 de Lecea L, Kilduff TF, Peyron C, Gao XB, Foye PE, Danielson PE, et al: The hypocretins: hypothalamus-specific peptides with neuroexcitatory activity. Proc Natl Acad Sci USA 1998;95:322-327.

11 Sakurai T, Amemiya A, Ishii M, Matsuzaki I, Chemelli $\mathrm{RM}$, Tanaka $\mathrm{H}$, et al: Orexins and orexin receptors: a family of hypothalamic neuropeptides and $\mathrm{G}$ proteincoupled receptors that regulate feeding behavior. Cell 1998;92:573-585

12 Xu T-R, Yang Y, Ward R, Gao L, Liu Y: Orexin receptors: multi-functional therapeutic targets for sleeping disorders, eating disorders, drug addiction, cancers and other physiological disorders. Cell Signal 2013;25:24132423.

13 Trivedi P, Yu H, MacNeil DJ, Van der Ploeg LH, Guan XM: Distribution of orexin receptor mRNA in the rat brain. FEBS Lett 1998;438:71-75.

14 Li Y, Gao XB, Sakurai T, van den Pol AN: Hypocretin/ Orexin excites hypocretin neurons via a local glutamate neuron-A potential mechanism for orchestrating the hypothalamic arousal system. Neuron 2002;36:11691181.

15 Xie X, Crowder TL, Yamanaka A, Morairty SR, Lewinter $\mathrm{RD}$, Sakurai T, et al: GABA(B) receptor-mediated modulation of hypocretin/orexin neurones in mouse hypothalamus. J Physiol 2006;574:399-414. 
16 Yamanaka A, Muraki Y, Tsujino N, Goto K, Sakurai T: Regulation of orexin neurons by the monoaminergic and cholinergic systems. Biochem Biophys Res Commun 2003;303:120-129.

17 Liu R-J, van den Pol AN, Aghajanian GK: Hypocretins (orexins) regulate serotonin neurons in the dorsal raphe nucleus by excitatory direct and inhibitory indirect actions. J Neurosci 2002;22:9453-9464.

18 Hagan JJ, Leslie RA, Patel S, Evans ML, Wattam TA, Holmes S, et al: Orexin A activates locus coeruleus cell firing and increases arousal in the rat. Proc Natl Acad Sci USA 1999;96:10911-10916.

19 Huang ZL, Qu WM, Li WD, Mochizuki T, Eguchi N, Watanabe T, et al: Arousal effect of orexin A depends on activation of the histaminergic system. Proc Natl Acad Sci USA 2001;98:9965-9970.

20 Eggermann E, Serafin M, Bayer L, Machard D, SaintMleux B, Jones BE, et al: Orexins/hypocretins excite basal forebrain cholinergic neurones. Neuroscience 2001; 108:177-181.

21 Nambu T, Sakurai T, Mizukami K, Hosoya Y, Yanagisawa M, Goto K: Distribution of orexin neurons in the adult rat brain. Brain Res 1999;827:243-260.

22 Peyron C, Tighe DK, van den Pol AN, de Lecea L, Heller HC, Sutcliffe JG, et al: Neurons containing hypocretin (orexin) project to multiple neuronal systems. J Neurosci 1998;18:9996-10015.

23 Fogel SM, Smith CT, Beninger RJJ: Increased GABAergic activity in the region of the pedunculopontine and deep mesencephalic reticular nuclei reduces REM sleep and impairs learning in rats. Behav Neurosci 2010;124: 79-86.

24 Mieda M, Hasegawa E, Kisanuki YY, Sinton CM, Yanagisawa M, Sakurai T: Differential roles of orexin receptor- 1 and -2 in the regulation of Non-REM and REM sleep. J Neurosci 2011;31:6518-6526.

25 Chen Q, de Lecea L, Hu Z, Gao D: The hypocretin/orexin system: an increasingly important role in neuropsychiatry. Med Res Rev 2015;35:152-197.

26 Deadwyler SA, Porrino L, Siegel JM, Hampson RE: Systemic and nasal delivery of orexin-A (hypocretin-1) reduces the effects of sleep deprivation on cognitive performance in nonhuman primates. J Neurosci 2007;27: 14239-14247.

27 Lambe EK, Olausson P, Horst NK, Taylor JR, Aghajanian GK: Hypocretin and nicotine excite the same thalamocortical synapses in prefrontal cortex: correlation with improved attention in rat. J Neurosci 2005;25: 5225-5229.

28 Calva CB, Fayyaz H, Fadel JR: Effects of intranasal orexin-A (hypocretin-1) administration on neuronal activation, neurochemistry, and attention in aged rats. Front Aging Neurosci 2019;11:362.

29 Yang L, Zou B, Xiong X, Pascual C, Xie J, Malik A, et al: Hypocretin/orexin neurons contribute to hippocampusdependent social memory and synaptic plasticity in mice. J Neurosci 2013;33:5275-5284.

30 Boschen KE, Fadel JR, Burk JA: Systemic and intrabasalis administration of the orexin-1 receptor antagonist, SB-334867, disrupts attentional performance in rats. Psychopharmacology 2009;206:205-213.
31 Dietrich H, Jenck F: Intact learning and memory in rats following treatment with the dual orexin receptor antagonist almorexant. Psychopharmacology 2010;212: 145-154.

32 Uslaner JM, Tye SJ, Eddins DM, Wang X, Fox SV, Savitz AT, et al: Orexin receptor antagonists differ from standard sleep drugs by promoting sleep at doses that do not disrupt cognition. Sci Transl Med 2013;5:179ra44.

33 Tannenbaum PL, Tye SJ, Stevens J, Gotter AL, Fox SV, Savitz AT, et al: Inhibition of orexin signaling promotes sleep yet preserves salient arousability in monkeys. Sleep 2016;39:603-612.

34 Neylan TC, Richards A, Metzler TJ, Ruoff LM, Varbel J, O'Donovan A, et al: Acute cognitive effects of the hypocretin receptor antagonist almorexant relative to zolpidem and placebo: a randomized clinical trial. Sleep 2020;43:zsaa080.

35 Roth T, Zammit G, Mignot E, Leger D, Bassetti C, Pain $S$, et al: Daridorexant, a novel dual orexin receptor antagonist, delivers significant improvement in sleep parameters and daytime function for patients with insomnia disorder. J Sleep Res 2020;29:P167.

36 Herring WJ, Connor KM, Ivgy-May N, Snyder E, Liu K, Snavely DB, et al: Suvorexant in patients with insomnia: results from two 3-month randomized controlled clinical trials. Biol Psychiatry 2016;79:136-148.

37 Murphy P, Moline M, Mayleben D, Rosenberg R, Zammit G, Pinner K, et al: Lemborexant, a dual orexin receptor antagonist (DORA) for the treatment of insomnia disorder: results from a Bayesian, adaptive, randomized, double-blind, placebo-controlled study. J Clin Sleep Med 2017;13:1289-1299.

38 Gélineau J: De la narcolepsie. Gaz Hop 1880;53;54:626$628 ; 735-737$.

39 Henneberg R: Über genuine narkolepsie. Neurol Zbl 1916;30:282-290.

40 Plazzi G, Serra L, Ferri R: Nocturnal aspects of narcolepsy with cataplexy. Sleep Med Rev 2008;12:109-128.

41 Longstreth WTJ, Koepsell TD, Ton TG, Hendrickson AF, van Belle G: The epidemiology of narcolepsy. Sleep 2007;30:13-26.

42 Ripley B, Overeem S, Fujiki N, Nevsimalova S, Uchino $\mathrm{M}$, Yesavage J, et al: CSF hypocretin/orexin levels in narcolepsy and other neurological conditions. Neurology 2001;57:2253-2258.

43 Nishino S, Ripley B, Overeem S, Nevsimalova S, Lammers GJ, Vankova J, et al: Low cerebrospinal fluid hypocretin (orexin) and altered energy homeostasis in human narcolepsy. Ann Neurol 2001;50:381-388.

44 Dauvilliers Y, Siegel JM, Lopes R, Torontali ZA, Peever J: Cataplexy-clinical aspects, pathophysiology and management strategy. Nat Rev Neurol 2014;10:386-395.

45 Mahoney CE, Cogswell A, Koralnik IJ, Scammell TE: The neurobiological basis of narcolepsy. Nat Rev Neurosci 2019;20:83-93.

46 Hood B, Bruck D: Metamemory in narcolepsy. J Sleep Res 1997;6:205-210.

47 Rieger M, Mayer G, Gauggel S: Attention deficits in patients with narcolepsy. Sleep 2003;26:36-43. 
48 Henry GK, Satz P, Heilbronner RL: Evidence of a perceptual-encoding deficit in narcolepsy? Sleep 1993;16: 123-127.

49 Moraes M, Rossini S, Reimāo R: Executive attention and working memory in narcoleptic outpatients. Arq Neuropsiquiatr 2012;70:335-340.

50 Zamarian L, Högl B, Delazer M, Hingerl K, Gabelia D, Mitterling T, et al: Subjective deficits of attention, cognition and depression in patients with narcolepsy. Sleep Med 2015;16:45-51.

51 Fulda S, Schulz H: Cognitive dysfunction in sleep disorders. Sleep Med Rev 2001;5:423-445.

52 Bayard S, Langenier MC, Cock CD, Scholz S, Dauvilliers Y: Executive control of attention in narcolepsy. PLoS One 2012;7:1-8.

53 Ponz A, Khatami R, Poryazova R, Werth E, Boesiger P, Bassetti CL, et al: Abnormal activity in reward brain circuits in human narcolepsy with cataplexy. Ann Neurol 2010;67:190-200.

54 Bayard S, Abril B, Yu H, Scholz S, Carlander B, Dauvilliers Y: Decision making in narcolepsy with cataplexy. Sleep 2011;34:99-104.

55 Bayard S, Dauvilliers YA: Reward-based behaviors and emotional processing in human with narcolepsy-cataplexy. Front Behav Neurosci 2013;7:50.

56 Mieda M, Willie JT, Hara J, Sinton CM, Sakurai T, Yanagisawa M: Orexin peptides prevent cataplexy and improve wakefulness in an orexin neuron-ablated model of narcolepsy in mice. Proc Natl Acad Sci USA 2004; 101:4649-4654

57 Weinhold SL, Seeck-Hirschner M, Nowak A, Hallschmid M, Goder R, Baier PC: The effect of intranasal orexin-A (hypocretin-1) on sleep, wakefulness and attention in narcolepsy with cataplexy. Behav Brain Res 2014;262:8-13.

58 Baier PC, Hallschmid M, Seeck-Hirschner M, Weinhold SL, Burkert S, Diessner N, et al: Effects of intranasal hypocretin-1 (orexin A) on sleep in narcolepsy with cataplexy. Sleep Med 2011;12:941-946.

59 Lehert P, Falissard B: Multiple treatment comparison in narcolepsy: a network meta-analysis. Sleep 2018; 41;zsy185.

60 American Psychiatric Association: Diagnostic and Statistical Manual of Mental Disorders (Fifth Edition). Arlington, American Psychiatric Association, 2013.

61 Guillaume S, Gorwood P, Jollant F, Van den Eynde F, Courtet P, Richard-Devantoy S: Impaired decision-making in symptomatic anorexia and bulimia nervosa patients: a meta-analysis. Psychol Med 2015;45:3377-3391.

62 Steward T, Mestre-Bach G, Granero R, Sanchez I, Riesco $\mathrm{N}$, Vintro-Alcaraz C, et al: Reduced plasma orexin-A concentrations are associated with cognitive deficits in anorexia nervosa. Sci Rep 2019;9:7910.

63 Herbrich L, Kappel V, van Noort BM, Winter S: Differences in set-shifting and central coherence across anorexia nervosa subtypes in children and adolescents. Eur Eat Disord Rev 2018;26:499-507.

64 Steinglass JE, Lempert KM, Choo T-H, Kimeldorf MB, Wall M, Walsh BT, et al: Temporal discounting across three psychiatric disorders: anorexia nervosa, obsessive compulsive disorder, and social anxiety disorder. Depress Anxiety 2017;34:463-470.
65 Bronsky J, Nedvidkova J, Krasnicanova H, Vesela M, Schmidtova J, Koutek J, et al: Changes of orexin A plasma levels in girls with anorexia nervosa during eight weeks of realimentation. Int J Eat Disord 2011;44:547552.

66 Janas-Kozik M, Stachowicz M, Krupka-Matuszczyk I, Szymszal J, Krysta K, Janas A, et al: Plasma levels of leptin and orexin $\mathrm{A}$ in the restrictive type of anorexia nervosa. Regul Pept 2011;168:5-9.

67 Sauchelli S, Jimenez-Murcia S, Sanchez I, Riesco N, Custal N, Fernandez-Garcia JC, et al: Orexin and sleep quality in anorexia nervosa: clinical relevance and influence on treatment outcome. Psychoneuroendocrinology 2016;65:102-108.

68 Sarter M, Turchi J: Age- and dementia-associated impairments in divided attention: psychological constructs, animal models, and underlying neuronal mechanisms. Dement Geriatr Cogn Disord 2002;13:46-58.

69 Oken BS, Kishiyama SS, Kaye JA, Howieson DB: Attention deficit in Alzheimer's disease is not simulated by an anticholinergic/antihistaminergic drug and is distinct from deficits in healthy aging. Neurology 1994;44:657662.

70 Kessler BA, Stanley EM, Frederick-Duus D, Fadel J: Agerelated loss of orexin/hypocretin neurons. Neuroscience 2011;178:82-88.

71 Terao A, Apte-Deshpande A, Morairty S, Freund YR, Kilduff TS: Age-related decline in hypocretin (orexin) receptor 2 messenger RNA levels in the mouse brain. Neurosci Lett 2002;332:190-194.

72 Espana RA, Baldo BA, Kelley AE, Berridge CW: Wakepromoting and sleep-suppressing actions of hypocretin (orexin): basal forebrain sites of action. Neuroscience 2001;106:699-715.

73 Fadel J, Pasumarthi R, Reznikov LR: Stimulation of cortical acetylcholine release by orexin A. Neuroscience 2005; 130:541-547.

74 Fadel J, Frederick-Duus D: Orexin/hypocretin modulation of the basal forebrain cholinergic system: insights from in vivo microdialysis studies. Pharmacol Biochem Behav 2008;90:156-162.

75 Arrigoni E, Mochizuki T, Scammell TE: Activation of the basal forebrain by the orexin/hypocretin neurones. Acta Physiol (Oxf) 2010;198:223-235.

76 Horne J: Exercise benefits for the aging brain depend on the accompanying cognitive load: insights from sleep electroencephalogram. Sleep Med 2013;14:1208-1213.

77 DeTure MA, Dickson DW: The neuropathological diagnosis of Alzheimer's disease. Mol Neurodegener 2019; 14:32.

78 Slats D, Claasen JA, Lammers GJ, Melis RJ, Verbeek MM, Overeem S: Association between hypocretin-1 and amyloid- $\beta 42$ cerebrospinal fluid levels in Alzheimer's disease and healthy controls. Curr Alzheimer Res 2012; 9:1119-1125.

79 Liguori C, Nuccetelli M, Izzi F, Sancesario G, Romigi A, Martorana A, et al: Rapid eye movement sleep disruption and sleep fragmentation are associated with increased orexin-A cerebrospinal-fluid levels in mild cognitive impairment due to Alzheimer's disease. Neurobiol Aging 2016;40:120-126. 
80 Liu Z, Wang F, Tang M, Zhao Y, Wang X: Amyloid $\beta$ and tau are involved in sleep disorder in Alzheimer's disease by orexin A and adenosine A(1) receptor. Int J Mol Med 2019;43:435-442.

81 Kang J-E, Lim MM, Bateman RJ, Lee JJ, Smyth LP, Cirrito JR, et al: Amyloid-beta dynamics are regulated by orexin and the sleep-wake cycle. Science 2009;326: 1005-1008.

82 Brzecka A, Leszek J, Ashraf GM, Ejma M, Ávila-Rodriguez MF, Yarla NS, et al: Sleep disorders associated with Alzheimer's disease: a perspective. Front Neurosci 2018; 12:330.

83 Fronczek R, van Geest S, Frolich M, Overeem S, Roelandse FWC, Lammers GJ, et al: Hypocretin (orexin) loss in Alzheimer's disease. Neurobiol Aging 2012;33: 1642-1650

84 Roh JH, Jiang H, Finn MB, Stewart FR, Mahan TE, Cirrito JR, et al: Potential role of orexin and sleep modulation in the pathogenesis of Alzheimer's disease. J Exp Med 2014;211:2487-2496.

85 Xie L, Kang H, Xu Q, Chen MJ, Liao Y, Thiyagarajan M, et al: Sleep drives metabolite clearance from the adult brain. Science 2013;342:373-377.

86 Vyazovskiy VV, Olcese U, Lazimy YM, Faraguna U, Esser SK, Williams JC, et al: Cortical firing and sleep homeostasis. Neuron. 2009;63:865-878.

87 Ju YES, Lucey BP, Holtzman DM: Sleep and Alzheimer disease pathology - a bidirectional relationship. Nat Rev Neurol 2014;10:115-119.

88 Homolak J, Mudrovčić M, Vukić B, Toljan K: Circadian rhythm and Alzheimer's disease. Med Sci 2018;6:52.

89 Duncan MJ, Farlow H, Tirumalaraju C, Yun DH, Wang C, Howard JA, et al: Effects of the dual orexin receptor antagonist DORA-22 on sleep in 5XFAD mice. Alzheimers Dement Transl Res Clin Interv 2019;5:70-80.

90 Tan LCS: Mood disorders in Parkinson's disease. Parkinsonism Relat Disord 2012;18(suppl 1):S74-S76.

91 Davis AA, Racette B: Parkinson disease and cognitive impairment: five new things. Neurol Clin Pract 2016;6: 452-458.

92 Wienecke M, Werth E, Poryazova R, Baumann-Vogel H, Bassetti CL, Weller M, et al: Progressive dopamine and hypocretin deficiencies in Parkinson's disease: is there an impact on sleep and wakefulness? J Sleep Res 2012; 21:710-717.

93 Drouot X, Moutereau S, Nguyen JP, Lefaucheur JP, Creange A, Remy P, et al: Low levels of ventricular CSF orexin/hypocretin in advanced PD. Neurology 2003;61: 540-543.

94 Fronczek R, Overeem S, Lee SYY, Hegeman IM, van Pelt J, van Duinen SG, et al: Hypocretin (orexin) loss in Parkinson's disease. Brain 2007;130:1577-1585.
95 Thannickal TC, Lai Y-Y, Siegel JM: Hypocretin (orexin) cell loss in Parkinson's disease. Brain 2007;130: 1586-1595.

96 Bridoux A, Moutereau S, Covali-Noroc A, Margarit L, Palfi S, Nguyen JP, et al: Ventricular orexin-A (hypocretin-1) levels correlate with rapid-eye-movement sleep without atonia in Parkinson's disease. Nat Sci Sleep 2013;5:87-91.

97 Baumann CR, Scammell TE, Bassetti CL: Parkinson's disease, sleepiness and hypocretin/orexin. Brain 2008; 131:e91.

98 Howells DW, Porritt MJ, Wong JYF, Batchelor PE, Kalnins R, Hughes AJ, et al: Reduced BDNF mRNA expression in the Parkinson's disease substantia nigra. Exp Neurol 2000;166:127-135.

99 Liu C, Xue Y, Liu MF, Wang Y, Liu ZR, Diao HL, et al: Orexins increase the firing activity of nigral dopaminergic neurons and participate in motor control in rats. J Neurochem 2018;147:380-394.

100 Hadadianpour Z, Fatehi F, Ayoobi F, Kaeidi A, Shamsizadeh A, Fatemi I: The effect of orexin-A on motor and cognitive functions in a rat model of Parkinson's disease. Neurol Res. 2017;39:845-851.

101 Stanojlovic M, Pallais JP, Lee MK, Kotz CM: Pharmacological and chemogenetic orexin/hypocretin intervention ameliorates Hipp-dependent memory impairment in the A53T mice model of Parkinson's disease. Mol Brain 2019;12:87.

102 Rasch B, Born J: About sleep's role in memory. Physiol Rev United States 2013;93:681-766.

103 Smith CT: REM sleep and learning: some recent findings; in Moffitt Kramer M, Hoffmann RA (eds): The Functions of Dreaming. New York, SUNY Press, 1993, pp 341-361.

104 Fogel SM, Ray LB, Binnie L, Owen AM: How to become an expert: a new perspective on the role of sleep in the mastery of procedural skills. Neurobiol Learn Mem 2015;125:236-248.

105 Fogel SM, Albouy G, King BR, Lungu O, Vien C, Boré A, et al: Reactivation or transformation? Motor memory consolidation associated with cerebral activation time-locked to sleep spindles. PLoS One 2017; 12:e0174755.

106 Jegou A, Schabus M, Gosseries O, Dahmen B, Albouy $\mathrm{G}$, Desseilles $\mathrm{M}$, et al: Cortical reactivations during sleep spindles following declarative learning. Neuroimage 2019;195:104-112.

107 Villano I, Messina A, Valenzano A, Moscatelli F, Esposito $\mathrm{T}$, Monda $\mathrm{V}$, et al. Basal forebrain cholinergic system and orexin neurons: effects on attention. Front Behav Neurosci 2017;11:10.
Stuart M. Fogel

School of Psychology

University of Ottawa

136 Jean-Jacques Lussier, Ottawa, ON K1N 6N5 (Canada)

sfogel@uottawa.ca 